\title{
KNOWLEDGE MANAGEMENT PRINCIPLES
}

\author{
Mrs Marlize Breedt \\ Prof Antonie van Rensburg \\ Department of Industrial and System Engineering \\ University of Pretoria \\ e-mail: acj@iafrica.com
}

\begin{abstract}
Business drivers such as digitisation, globalisation, customer intimacy and the emergence of the Information Age initiate the need to manage the organisation's knowledge asset. Knowledge management aims at leveraging this explicit and tacit knowledge asset to the collective benefit of the organisation by developing an infrastructure to facilitate the knowledge process and by making information readily available. The implementation of such an initiative requires integration of the strategic, process, human resource, and technology architecture components as the company's competitive advantage depends on the quality of the organisation's knowledge asset and successful exploitation of it.
\end{abstract}

\section{OPSOMMING}

Veranderingsdrywers soos digitalisering, globalisering, kliënteverhoudings en die ontstaan van die inligtingsera inisieer die behoefte om organisasiekennishulpbronne te bestuur. Kennisbestuur het ten doel om die eksplisiete en nie-eksplisiete kennishulpbron tot die gesamentlike voordeel van die organisasie aan te wend deur ' $n$ infrastruktuur daar te stel om die kennisproses te fasiliteer en inligting beskikbaar te stel. Die implementering van ' $n$ kennisbestuursinisiatief vereis integrasie van die strategiese-, proses-, menslikehulpbron-, en tegnologieargitektuur komponente ten einde die kompeterende voordeel van die organisasie te behou. Onderliggend tot die sukses is die vermoë en kwaliteit van die organisasie se kennishulpbronne. 


\section{INTRODUCTION}

'The only sustainable source of advantage is the ability to learn faster than your competitors.' - A. Geus

Transformation from the Industrial to the Information Age implies a change in the rules of business. The traditional view that sustainable competitive advantage [8] depends on the five forces of customers, suppliers, buyers, new entrants, and competitors is being influenced by three new forces - digitisation, deregulation, and globalisation [3]. This changes the leveragability of the traditional five forces by enabling new entrants in a new way. These forces serve as business drivers to adapt and utilise the knowledge assets embedded in the mobile workforce.

Survival in the Information Age depends on an organisation's ability to capture data, filter useful information, transform it into usable knowledge, disseminate it via organisational learning, and diffuse it rapidly to where it is required. Knowledge management entails the use and re-use of intellectual assets created and developed in the organisation to generate solutions for the client.

This article introduces knowledge management as a discipline by considering the change drivers that initiated the need for this new business initiative and the characteristics of the knowledge asset. The rest of the discussion is focused on the definition of knowledge management and knowledge management principles.

\section{DRIVERS OF KNOWLEDGE MANAGEMENT}

"In this society, knowledge is the primary resource for individuals and the economy overall." - P. Drucker

As we leave the industrial era behind and move into the knowledge age, the sources of wealth and competitive advantage for organisations are changing. The primary capital assets needed to create wealth are no longer land, physical labour, machine tools and factories, but rather the "application of knowledge" [4]. Stewart is of the opinion that: "Knowledge has become the most important factor in economic life. It is the chief ingredient of what we buy and sell and the raw material with which we work. Intellectual capital has become the one indispensable asset of the corporation. In industry after industry, success comes to companies that have the best information and wield it most effectively" [11]. The resource-based economy (agriculture, production, and mining) is still subject to the principle of diminishing returns.

Those parts of the economy that are knowledge-based, are subject to increasing returns. These include products such as computers, pharmaceuticals, software, telecommunication equipment, and fibre optics, which are complex to design and to manufacture. The development cost of knowledge-intensive goods is heavily frontloaded as the cost of creating the first product is disproportionately higher than the 
last. Consequently there is no definite correlation between the value of intellectual capital and the cost of acquiring it.

Changing forces that brought about the Knowledge Age have introduced a new environment with new business rules. The knowledge content of a product distinguishes it from other products with its brand name making the sale. This marketspace is not restricted to time, information or geographical barriers but rather guided by principles such as [3]:

- Moore's Law indicating that digital technology becomes increasingly cheaper, smaller, and faster with replacing atoms for bits.

口 In the digital revolution the traditional barriers to entry of infrastructure and fixed assets do not hold any more and turn out to be liabilities.

- Metcalfe's law stating that the value of an open system or a network becomes exponentially more valuable to its users as more people use it, once it reaches critical mass.

- The Law of Disruption explains that the exponential amount of changes in technology is responsible for major secondary effects on other unrelated systems.

口 Transaction cost minimises because of the economies of cyberspace. Consequently organisations that exist to optimise transaction cost with economies of scale will become ineffective. This brings about the law of diminishing firms where the reduction of the market's transaction cost implies the decrease in the organisation's size.

ㅁ The property of information is accepted as public goods and should be given away for free.

In this new environment the only competitive advantage depends on the quality of the organisation's knowledge assets and their successful exploitation of it [14]. The company can retain a balanced portfolio of intellectual capital to develop products based on the 'economics of ideas' by managing the knowledge or the organisation's capacity to solve problems, to innovate, to remember without continually re-inventing the wheel, as well as to build on experience and skills.

\section{Digitisation}

To eliminate the need for additional information capturing activities it becomes increasingly important to capture information at the source as part of the knowledge worker's daily activities. Once information is effectively indexed, transported, stored, and distributed, value-added information becomes accessible. For this reason the participation in, and especially contribution to, Knowledge Management Systems (KMS) should become an ingrained aspect of the daily routine of every type of knowledge worker in the organisation. 


\section{Globalisation}

An open system or network reaches critical mass if its users exponentially value the use of it. The network utility of such a system is described as the square of its number of users. The Internet's Communication Protocol, due to its openness, reached critical mass in 1993 and has become an open market for the sharing, using, and adding of information to the global information base [3]. For this reason it is essential that the organisation manage this new source of information to enhance its knowledge asset.

\section{Costly Reinvention}

Organisations can save on the 'reinventing the wheel' syndrome by retaining knowledge through recorded lessons learned and leveraging knowledge so that the whole company can do the job faster next time. By taking the knowledge from expert performers and applying it in similar situations, companies are able to develop this as a competence of the organisation.

\section{Customer Intimacy}

The primary value discipline of our age is the ability to quickly provide problem solutions to customers [10]. Through Internet technology mass customisation is becoming a reality. This means that the customer interacts with a personal interface according to his personal preferences that gives the company in return valuable marketing information on the customer's behaviour.

\section{THE KNOWLEDGE ASSET}

'The knowledge and skills of employees is what really differentiates a firm from its competitors.' $\mathrm{R}$. Tobin

Every employee builds a wealth of knowledge through learning and skills development. Thus employees have valuable knowledge for the benefit of the company; yet most of this knowledge is not harnessed to the collective benefit of the organisation. The aim of knowledge management is to develop a knowledge base equal to all employees' knowledge, skills, behaviour, perceptions, values, principles, and education within the organisation's specific culture (leadership style, management style, communication and organisational behaviour), strategy, and structure.

\section{Definition of Knowledge}

Prior to define knowledge management, differences between data, information and knowledge have to be clarified. Knowledge is what is learned or retained from data or 
information - that is where and how to find information as well as to understand and comprehend the information, developing beliefs, values, and ultimately establishing wisdom. Due to the way knowledge is created from data and information no clear relationship exists between the cost of creating knowledge and the ultimate value derived from knowledge. This distinguishes it from other resources such as land, labour or capital in the way that knowledge is infinite, expandable and selfgenerating, transportable at dramatic speed and increases with sharing.

In order for a thought to become knowledge it should be shared, distributed, and challenged. Knowledge does not belong to an individual but is the source in which everybody shares and to which everybody contributes. Knowledge becomes an asset when some useful order is created out of free-floating brainpower - that is, when it is given coherent form (a mailing list, a database, an agenda for a meeting, or a description of a process). When captured in a way that allows it to be described, shared, exploited and appropriately packaged it becomes intellectual capital.

\section{Intellectual Capital}

'Intellectual capital is the sum of everything everybody in a company knows that gives it a competitive advantage. '- T. Stewart

The difference between the book value of a company according to its balance sheet and its selling price, usually comprises its intellectual assets, such as expected revenues from patents, customer relationships, brand names, and ability of management. Stock markets put premiums on knowledge asset value if it rates the organisation much higher than its book value. This shows the difference in the value of tangible, measurable hard assets and intangibles; people, brand name and management assets [11]. Intellectual capital combines human knowledge with structural capital (i.e. the tools which are used to package human capital and permit it to be used time and again in the creation of value) as well as customer capital (i.e. knowledge of the market and the organisation's stakeholders). The development of human, customer and structural capital is the company's essential intellectual assets [5].

\section{Internal Capital}

A person's mental model is the representation of reality within a certain frame of reference while using mental processes to think and to solve problems. The combined result of the employees' mental models determines the thinking ability of the company and quality of decision making. The "intelligence" of companies depends on how good they use the mind power of their employees as their knowledge resource, through an up-to-date knowledge base, built by formal education and learning at work.

\section{Structural Capital}

'Even the smartest people in the world need a mechanism to assemble, package, promote, and distribute the fruits of their thinking.' - T. Stewart 
Organisations are under enormous strain with regards to the management of knowledge. Studies show that employees spend $35 \%$ of their time looking for information that others already have. Furthermore with a $10 \%$ annual turnover of employees, organisations lose half of their experienced workers within five years. As a result, companies need to make newcomers learn what the organisation already knows so that they can start contributing to the organisation as soon as possible. Key to address these issues and threats is to utilise knowledge assets through the reuse of shared knowledge and experience as well as structuring and packaging competencies with technology, manuals, and process descriptions to ensure that knowledge remains in the organisation.

Companies need the ability to collect and manage unstructured information, whether from the Internet or an Intranet, whether it is documented or not, with some sort of repository facility to store it. They need to retain knowledge so that it becomes organisational property by creating structural capital. Intellectual property is the knowledge assets which can be legally protected, with the legal rights of ownership, in the form of patents, trade marks, trade secrets, copyrights, and products/services.

\section{Customer Capital}

Companies should invest in its employees and structures as well as in its customers. Companies who establish connectivity with their clients benefit from these relationships which is considered to be one of the best sources of knowledge to help a company with the innovation of new products. The reality is that the success of the customer feeds the organisation's success and that long-term monetary value depends on customer loyalty and the value of the company's brand name.

\section{DEFINITION OF KNOWLEDGE MANAGEMENT}

'Knowledge management is simply delivering the right information, to the right person, at the right time and place, to make a business decision of value to the enterprise.' - J. Libit

Knowledge management is a discipline that promotes an integrated approach to the identification, capturing, retrieval, sharing, and evaluation of information assets of an enterprise. This includes databases, documents, policies and procedures as well as the uncaptured, tacit expertise and experience resident in individual workers. It allows organisations to continually update and renew organisation-specific information, which is then made available to the appropriate individuals within the organisation. As this enhances the knowledge and skills of employees, performance of the organisation is impacted in the whole. This surpasses the goals of efficiency and performance of the organisation to address the sense of worth and feelings of adequacy and contribution by the individual, resulting in job satisfaction and improved performance. 
The purpose of knowledge management within an organisation is thus to create a knowledge base that contains up-to-date, organisation-specific information, which is accurate and secure. Furthermore it should be supported by an infrastructure that is easily accessible, edited, updated and organised to simplify search and maintenance, making information readily available to all appropriate individuals in a cost effective way. Finally, it provides the opportunity to communicate through the sharing of information, ideas, and opinions.

\section{KNOWLEDGE MANAGEMENT PRINCIPLES}

To understand knowledge management, its role in the organisation, and the potential value-added to economic activities, a number of principles have to be supported, namely that of communities of interest, the knowledge market, knowledge management roles, and different ways to develop the company's knowledge stock.

\section{Communities of Interest}

'A group of professionals, informally bound to one another through exposure to a common class of problems, common pursuit of solutions, and thereby themselves embodying a store of knowledge.' - P. Manville

Communities of interest [11] or learning groups emerge on their own through social and professional forces. Group members use each other as soundboards, collaborate, give advice and explore new subject matter, creating a breeding ground for new ideas, knowledge transfer, and innovation. These groups are voluntary, develop over time, and are the result of a common interest or problem, involve learning, while maintaining a unique culture. They are defined as virtual environments in which entities with convergent interests and needs congregate to collect, share, exchange, and disseminate information and knowledge. Such an environment could be a Web site, a selected set of Web sites, or the corporate Intranet.

Organisations need to create a vibrant learning community and socialise human capital in order to retain knowledge ownership, even if parts of the community should leave the company, thus fostering intellectual communities in areas contributing to the competitive advantage of the organisation. Management can foster the growth of such communities by recognising them and their importance, make resources available, create cross-organisational communication systems, and frequently moving employees to enable new work-related relationships. These communities tend to be driven by their own little learning enterprise rather than the total organisation which cannot function within boundaries, as boundaries hamper the free flow of information. 


\section{Knowledge Market}

Knowledge flows through the organisation regulated by the same principles as market forces. Markets for knowledge exist within the organisation, because of the scarcity of the knowledge resource and knowledge transfer transactions occur because participants believe they will gain value from the interaction.

The roles in a knowledge market center around buyers, sellers, and brokers [2]. A buyer is someone that needs insight, judgement, and understanding in order to solve a difficult problem. A knowledge seller has a reputation in the internal market as someone who has knowledge and is willing to share. Specific individuals in the organisation who are interested in the company as a whole, perform the role of the knowledge broker (gatekeeper) who is then responsible for connecting sellers and buyers.

The pricing system operating in the knowledge market has a number of intangible motivation factors. The "reciprocity" factor is a self-interest motive where the seller shares knowledge because he believes that he would be able to gain from the buyer in the future. The "reputation" factor motivates the seller because by selling he is perceived as knowledgeable and willing to share, which will enhance his position in the market for future buying. The last source of motivation is the "good will" factor where the seller finds personal pleasure in sharing his knowledge. All these motives depend on the level of trust sustained in the organisation, the level of participation of top management, and the amount of recognition the seller receives for sharing knowledge.

A number of indicators in the knowledge market refer the buyer to available sources of knowledge. These include education, position and informal networks. Both the formal structures of the individual's education and position within the organisation and the informal networks (word of mouth) indicate useful and reliable knowledge resources. The informal structures are more dynamic and rely on gossip for a frequent update. On the opposite an ineffective knowledge market is caused by:

- a lack of sufficient indicators where knowledge resides in the organisation;

- a lack of knowledge diffusion through the organisation due to differences in purchase power;

- an ineffective distribution system where employees have no time to investigate the knowledge market;

- the price of getting the most effective knowledge being too expensive, due to the distance between seller and buyer and the transaction cost involved in getting the knowledge;

- a monopoly where only one expensive resource exists and a scarcity exists due to knowledge hoarding or downsizing; 
- company principles which values original ideas in contras with the re-use of ideas and where employees will refuse to buy.

However, effective markets can be created by:

- developing an effective IT infrastructure to establish a virtual knowledge market;

- by developing a reward and recognition system for using the infrastructure;

- by providing top management support.

This will enhance the morale of the company and individual participation as well as knowledge stock while it is actively validated.

\title{
Knowledge Roles \& Skills
}

Management of knowledge assets requires new roles and responsibilities. Primarily knowledge management is everybody's responsibility and each individual is accountable for maintaining and sharing his knowledge. However, specific knowledge workers are assigned to extract knowledge from individuals, transfer it into a structural form, make it available for use, and perform maintenance activities. On a strategic level, responsibility for organisational knowledge assets are normally assigned to a senior manager from either Information Technology or Human Resources to act as a Chief Knowledge Officer (CKO). This responsibility entails responsibilities such as developing a sharing culture, facilitation of the technology infrastructure development, relationship management of external information sources, knowledge asset measurement and knowledge management strategy development.

\section{Developing the Knowledge Stock of the Company}

Knowledge stock of the organisation can be increased through acquisition, renting, dedicate sources, fusion, knowledge creation, knowledge networking and codification.

\begin{abstract}
Acquisition
The greatest feature of the knowledge asset is the difficulty of transferring it across organisational boundaries. It is dependent on time, investment, culture, political issues, and on a specific ecology for its existence. The organisation can hire employees and establish joint ventures to acquire knowledge but the acquisition depends on the recipient's absorption ability. The reasons for transfer failure is due to the recipient's stubbornness, resistance to change, pride, lack of time, and lack of trust in the source of knowledge as well as to the medium that influences the speed of transfer and the quality or depth of knowledge.
\end{abstract}




\section{Renting}

Another way to generate more knowledge stock is to rent knowledge sources by outsourcing research and development activities, contracting of consultants, or by licensing specific knowledge sources. This is a temporary knowledge source that requires effective knowledge transfer to retain it.

\section{Dedicated sources}

A dedicated group of people with a specific knowledge responsibility such as R\&D and libraries generates knowledge stock. Their challenge is to transfer or diffuse the tacit, internal, and know-how type of knowledge to the rest of the organisation, e.g. through mentoring, in order to retain and preserve individuals' knowledge.

\section{Fusion}

Combining different skills and ideas to generate creative chaos and innovative concepts can produce knowledge but require an overlap in the participants' knowledge bases.

\section{Knowledge Creation [7]}

Knowledge is created by any interaction between the tacit and explicit knowledge sources of the organization. The first dimension is knowledge from socialization that occurs when tacit knowledge is transformed to other tacit knowledge while people are in conversation. The result appears in the thoughts of those who participated in the process. The second dimension, externalization, is the transformation of tacit knowledge into an explicit form by codifying one's thoughts. The internalization dimension is the transformation of knowledge from an explicit into a tacit form - for example when one reads a book and absorbs it into one's own thoughts. The final dimension is the combination of different explicit knowledge sources such as the combining of different codified documents to generate a new document.

\section{Knowledge Networking}

The size of the organisation increases the probability that the required knowledge exists within the organisation but decreases the probability of finding it. This calls for strategies to initiate knowledge fairs where sellers and buyers can meet to discuss the knowledge available, with sufficient time and space to collaborate and generate knowledge. The channel for knowledge transfer depends on the type of knowledge. Tacit knowledge only transfers within a relationship and sufficient personal contact such as face-to-face meetings and informal conversation. This is true because through conversations the knowledge worker discovers what he knows, shares it, and processes new knowledge for the organisation [2]. 


\section{Codification}

Codified knowledge provides a portable, organised, explicit, and easy-tomanage entity. However, before codification commences it is important to consider the sources of this knowledge, the appropriate form of codification, and the means of knowledge distribution. This is highly dependent on a need for codification versus a need for linking as in some cases it is easier to link the enquirer with the source of knowledge (person), than to try and codify the tacit knowledge (for example, to transfer a builder's skill).

\section{CONCLUSION}

Knowledge management requires the ability to manage the intangible and tangible information assets of the corporation. The challenge for organisations is to unlock knowledge from employees tacit thought and experience. Major hurdles to overcome is the ability to ensure knowledge transfer quality as it is dependent on face-to-face employee contact, a sharing culture and the availability of an effective technology architecture. Thus, critical success factors for knowledge management initiatives will be to facilitate human knowledge networks, collective knowledge repositories and technologies, as well as having employees understand the paradigm of sharing knowledge to the benefit of the organisation.

The aim of knowledge management is not to limit knowledge but rather to encourage diversity of opinions and to allow learning to take place - to create and maintain superior knowledge it is necessary to make it available at point-of-action, whilst enabling a learning culture.

\section{REFERENCES}

[1] Davenport T. H., De Long D. W., Beers M. C., "Successful Knowledge Management Projects", Sloan Management Review, Vol. 39, No. 2, 1998.

[2] Davenport Thomas H., Prusak Laurence, "Working Knowledge - How Organisations Manage What They Know", Harvard Business School Press, Boston, Massachusetts, 1998.

[3] Downes L., Mui C., "Unleashing the Killer App Digital Strategies for Market Dominance", Harvard Business School Press, Boston, Massachusetts, 1998.

[4] Drucker P.F., "The age of social transformation", The Atlantic Monthly, p53-80, Nov 1994.

[5] Edvinsson L., "The identification of Intellectual Capital within the organisation: tapping its full potential', Data Warehousing \& Knowledge Management '98 Conference, Sandton, 1998.

[6] Grayson C. Jackson, Chairman of American Productivity \& Quality Centre

[7] Nonaka I., Takeuchi H. (Contributor), Takeuchi H., "The Knowledge-Creating Company : How Japanese Companies Create the Dynamics of Innovation", Oxford University Pr (Trade), 1995. 
[8] Porter Michael E., "Competitive Advantage: Creating and Sustaining Superior Performance", June 1998.

[9] Quinn J.B., Anderson P., Finkelstein S., "Managing Professional Capital: Making the Most of the Best", Harvard Business Review, p71-80, March-April 1994.

[10] Skyrme D., "Knowledge Management: Oxymoron Or Dynamic Duo", Managing Information, Vol. 4, No. 7, 1997.

[11] Stewart T.A., "Intellectual Capital', Nicholas Brealey Publishing, London, 1997. [12] Tobin Daniel R., "The Knowledge-Enabled Organization : Moving from 'Training' to 'Learning' to Meet Business Goals", AMACOM, 1997.

[13] Ulrich Dave, "Leading Lights: Author and Professor Dave Ulrich", Knowledge Inc, Vol. 3, No 3, p 8, Stamford, CT, March 1998.

[14] Wiig Karl M., "Executive Perspectives on the Importance of Knowledge", Chapter 2, p37-61, 1994. 